\title{
Localised pulmonary metastatic calcification associated with pulmonary artery obstruction
}

James Bloodworth, Joseph F Tomashefski Jr

\begin{abstract}
Background Metastatic pulmonary calcification, a complication of uraemia and disordered calcium metabolism, may be diffuse or localised. The factors that determine calcium precipitation are complex, but tissue alkalosis is thought to be important. As obstruction of the pulmonary artery theoretically causes local alkalosis a retrospective necropsy study was carried out to examine the relation between metastatic pulmonary calcification and vascular obstruction. Methods Five patients with focal and two with diffuse metastatic calcification in the lungs were identified over eight years. Lungs were studied macroscopically and by light microscopy, haematoxylin and eosin and histochemical stains being used for calcium.
\end{abstract}

Results Underlying risk factors for calcification in these patients included renal failure in six and disseminated malignancy in five. In the five patients with localised calcification obstruction of the pulmonary artery by thrombus or tumour was found proximal or adjacent to areas of calcium deposition. In two patients metastatic calcification was confined to a lung with unilateral pulmonary artery thromboembolic occlusion. Calcification was not specifically associated with infarction, pneumonia, or diffuse alveolar damage. Lesions of the pulmonary artery were not seen in the two patients with diffuse bilateral metastatic calcification.

Conclusion In this small series there was a spatial association between pulmonary artery obstruction and localised metastatic calcification. It is proposed that pulmonary artery obstruction alters the microchemical environment of the lung, favouring tissue alkalosis and thereby enhancing parenchymal calcification in patients predisposed to this condition.

Department of Pathology, Case Western Reserve University School of Medicine,

MetroHealth Medical

MetroHealth Medical

Road, Cleveland, Ohio

44109, USA

J Bloodworth

J F Tomashefski

Reprint requests to:

Dr Tomashefski

Accepted 15 November 1992
Metastatic calcification is an impor complication of disordered calcium metabobone disease, hyperparathyroidism, hype tion of phosphate and corticosteroids. ${ }^{12}$ Organs concerned with acid-base regulation, such as the lungs, kidneys, and stomach, are frequent sites of calcinosis. ${ }^{3}$ The mechanism of deposition of calcium salts is complex and is thought to be related to tissue $\mathrm{pH}$ and, variably, to an increase in the calciumphosphorus ion product. ${ }^{24}$

Metastatic pulmonary calcification, in which calcium salts encrust alveolar septa and blood vessels, may be diffuse or focal. ${ }^{5}$ Sporadic reports of localised pulmonary calcification have suggested that ventilation-perfusion $(\dot{\mathbf{V}}-\mathbf{Q})$ mismatching, resulting in an increased $\dot{\mathrm{V}}: \mathbf{Q}$ ratio, favours precipitation of calcium salts. ${ }^{67}$ In this report we describe a series of patients with unilateral or multifocal metastatic pulmonary calcification affecting lung parenchyma distal to obstructed pulmonary arteries. Our findings support the idea that $\dot{V}$ $Q$ abnormalities, presumably by altering tissue $\mathrm{pH}$, contribute to metastatic calcification in the lung.

\section{Methods}

We were stimulated to review cases of metastatic pulmonary calcification by finding at necropsy two patients (Nos 1 and 2) who had metastatic calcification in lungs with unilateral thromboembolic occlusion of proximal pulmonary arteries. We reviewed all cases in adults having a postmortem examination at our hospital from 1982 to 1990 . By reviewing necropsy reports and the notes of one of the authors (JFT) we identified seven patients-the subjects of this report-with metastatic pulmonary calcification, which is defined as the linear deposition of basophilic calcium salts on previously normal alveolar septa or blood vessel walls. Metastatic calcification is morphologically distinguished from dystrophic calcification, in which coarse, granular precipitates of calcium are deposited within inflammatory exudate, fibrin, fibrous tissue, or necrotic lung or tumour. ${ }^{4}$

\section{PATHOLOGICAL EXAMINATION}

Lungs were examined at the time of necropsy in a standard fashion. One lung was expanded with $10 \%$ neutral buffered formalin, instilled through the main bronchus at about $30-50 \mathrm{~cm}$ $\mathrm{H}_{2} \mathrm{O}$, and fixed for at least 24 hours. The lung was then sectioned in the coronal plane into slices $1 \mathrm{~cm}$ thick. The contralateral lung was sliced sagitally and examined while fresh. Representative tissue samples were embedded in paraffin, cut into sections 5-10 $\mu \mathrm{m}$ thick and stained with haematoxylin and eosin. In most cases calcification was verified with Alizarin red or Von Kossa stains (or both). Special consideration was given to the relation between parenchymal calcification and pulmonary 
Table 1 Clinical data

\begin{tabular}{|c|c|c|c|c|c|c|}
\hline \multirow{2}{*}{$\begin{array}{l}\text { Patient } \\
\text { No }\end{array}$} & \multirow{2}{*}{$\begin{array}{l}\text { Age } \\
(y)\end{array}$} & \multirow[b]{2}{*}{ Sex } & \multirow[b]{2}{*}{ Underlying disease } & \multicolumn{2}{|c|}{ Serum concentration $(\mathrm{mmol} / \mathrm{l})^{\star}$} & \multirow{2}{*}{$\begin{array}{l}\mathrm{Ca}-\mathrm{PO}_{4} \\
\text { ion } \\
\text { product }\end{array}$} \\
\hline & & & & $C a$ & $\mathrm{PO}_{4}$ & \\
\hline 1 & 22 & $\mathbf{F}$ & Nephrotic syndrome renal vein thrombosis & $2 \cdot 10$ & 2.52 & $65 \cdot 7$ \\
\hline 2 & 40 & $\mathbf{F}$ & Metastatic breast carcinoma & $2 \cdot 42 \dagger$ & 1.42 & $42 \cdot 7$ \\
\hline 3 & 22 & $\mathbf{M}$ & Thrombocythaemia, Budd-Chiari syndrome & $2 \cdot 5 \dagger$ & $2 \cdot 3$ & $71 \cdot 3$ \\
\hline 4 & 33 & $\mathbf{F}$ & $\begin{array}{l}\text { Metastatic small cell undifferentiated carcinoma of } \\
\text { ovary }\end{array}$ & 3.57 & $2 \cdot 03$ & $90 \cdot 0$ \\
\hline 5 & 63 & $\mathbf{F}$ & Metastatic breast carcinoma & $2 \cdot 54$ & 1.99 & $62 \cdot 7$ \\
\hline 6 & 67 & $\mathbf{M}$ & Multiple myeloma & $4 \cdot 04$ & $1 \cdot 36$ & $68 \cdot 2$ \\
\hline 7 & 43 & $\mathbf{M}$ & Metastatic squamous carcinoma of epiglottis & 4.09 & 1.94 & $98 \cdot 3$ \\
\hline
\end{tabular}

«The values are those associated with highest ion product. Normal values: serum calcium $2 \cdot 2-2.6 \mathrm{mmol} / \mathrm{l}$; serum phosphate $0.8-1.6 \mathrm{mmol} / \mathrm{l}$.

†Isolated serum calcium values were raised: $2.7 \mathrm{mmol} / 1$ (patient 2 ) and $2.8 \mathrm{mmol} / \mathrm{l}$ (patient 3 ).

artery obstruction. We reviewed the gross lung specimens that were available in five cases and macroscopic photographs of lungs in all cases.

\section{THE PATIENTS}

Three of the patients were men and four women, who ranged from 22 to 67 years of age (table 1). We reviewed hospital records and complete necropsy reports for all patients and chest radiographs for five.

In five patients (Nos 1-5) pulmonary calcification was focally distributed and in two (patients 6 and 7) bilateral and diffuse. Five patients (Nos 2, 4, 5, 6, 7) had disseminated malignancy with bone metastases. Patient 1 presented with renal failure due to the nephrotic syndrome and renal vein thrombosis and five others developed renal failure, which had lasted from seven days to three months. Four of these patients (Nos 1, 3, 5, and 6) required haemodialysis; patient 7 was treated with diuretics for a month before death; patient 4 had untreated anuria for a week before her death. The causes of renal failure were minimal change glomerulopathy with renal vein thrombosis (patient 1), acute tubular necrosis (patients 1, 3, 5, 6, 7) and hypovolaemia (patient 4). Serum calcium and phosphate concentrations ranged from low to raised (table 1). In one case (No 2) hypercalcaemia was treated with mithramycin. Pulmonary embolism was suspected clinically and treated with anticoagulants only in patient 1 . Two patients (Nos 1 and 6) developed respiratory failure compatible with the adult respiratory distress syndrome.

Metastatic calcification was not diagnosed, or even suspected, in any patient before death. The chest radiograph of patient 1 showed a left sided infiltrate in the lower two thirds of the lung field. The radiographs of the other four patients with focal calcification showed no relation between metastatic calcification and lung infiltrates.

\section{Results}

The pathological features associated with metastatic calcification are summarised in table 2. Gross examination showed foci of metastatic calcification appearing as granular yellow-tan to red-yellow areas of consolidation with accentuation of small airspaces (fig 1). Calcification was bilateral in four patients. The lung parenchyma was diffusely affected in two patients, the remaining patients showing focal zones of calcification in a lobular (patients $1,2,3,5$ ) or segmental (patient 4) distribution (fig 2).

In all patients metastatic calcification appeared histologically as linear, basophilic encrustation of alveolar septa and blood vessel walls (fig 1). Diffuse alveolar damage was seen in three patients and regional damage in two. ${ }^{89}$ Calcification was seen predominantly in areas

Table 2 Metastatic pulmonary calcification: pathological features

\begin{tabular}{|c|c|c|c|c|c|c|c|c|}
\hline $\begin{array}{l}\text { Patient } \\
\text { No }\end{array}$ & $\begin{array}{l}\text { Location of } \\
\text { calcification }\end{array}$ & $\begin{array}{l}\text { Vascular } \\
\text { obstruction }\end{array}$ & Infarct & Pneumonia & $D A D$ & $\begin{array}{l}\text { Extrapulmonic } \\
\text { calcification }\end{array}$ & $\begin{array}{l}\text { Lung } \\
\text { culture }\end{array}$ & $\begin{array}{l}\text { Other } \\
\text { findings }\end{array}$ \\
\hline 1 & Left lung & $T-E$, left main PA & + & + & + & - & Mixed bacteria $\star$ & $\begin{array}{l}\text { Renal vein } \\
\text { thrombosis }\end{array}$ \\
\hline 2 & Left lung & $\begin{array}{l}\text { T-E, left main, } \\
\text { lobar, segmental } \\
\text { PA }\end{array}$ & + & - &,$+ \mathrm{RAD}$ & - & $\begin{array}{l}\text { Pseudomonas } \\
\text { aeruginosa }\end{array}$ & $\begin{array}{l}\text { Metastatic } \\
\text { adenocarcinoma }\end{array}$ \\
\hline 3 & $\begin{array}{l}\text { Both lungs, } \\
\text { multifocal }\end{array}$ & $\begin{array}{c}\text { T-E, subsegmental } \\
\text { PA, bilateral }\end{array}$ & - & + & - & Liver, kidneys & $\begin{array}{l}\text { Mixed bacteria } \\
\text { Candida albicans }\end{array}$ & - \\
\hline 4 & $\begin{array}{l}\text { Right lower and } \\
\text { upper lobes }\end{array}$ & $\begin{array}{l}\text { Tumour invasion } \\
\text { RLL segmental } \\
\text { artery }\end{array}$ & + & - & - & - & Mixed bacteria & Metastatic carcinoma \\
\hline 5 & $\begin{array}{l}\text { Left upper lobe } \\
\text { and right lower } \\
\text { lobe }\end{array}$ & $\begin{array}{l}\text { T-E segmental LUL } \\
\text { PA }\end{array}$ & - & + &,$+ \mathrm{RAD}$ & - & Serratia sp & $\begin{array}{l}\text { Metastatic } \\
\text { adenocarcinoma }\end{array}$ \\
\hline 6 & Diffuse bilateral & - & - & + & + & $\begin{array}{l}\text { Heart, kidneys, } \\
\text { stomach, } \\
\text { oesophagus, trachea, } \\
\text { liver }\end{array}$ & Calbicans & $\begin{array}{l}\text { Acute alveolar } \\
\text { haemorrhage }\end{array}$ \\
\hline 7 & Diffuse bilateral & - & - & + & + & Stomach & Mixed bacteria & - \\
\hline
\end{tabular}

*Diagnosed by Gram stain only.

T-E-thromboembolus; PA-pulmonary artery; RAD—regional damage; DAD—diffuse alveolar damage; RLL—right lower lobe; LUL—left upper lobe. 
that showed diffuse alveolar damage in three patients $(1,6,7)$; in the others it was also seen in areas with no alveolar damage. Five patients had acute bronchopneumonia but this was extensive only in patient 1 . Metastatic calcification was not localised to the area of acute pneumonia. Cultures or Gram stains of postmortem lung tissue identified a mixture of Gram positive and negative bacteria in four patients, a single Gram negative organism in two patients, and Candida albicans in two patients.

In four of the five patients with focal calcification mineralisation occurred predominantly or

Figure 1 Patient 2: A Left lower lobe pulmonary artery occluded by an organised thromboembolus (large arrow). Metastatic calcification is present inferiorly at the base, giving pale, granular areas of parenchymal

consolidation. A healed infarct (small arrow) is present laterally, above the area of metastatic

calcification. The scale bar is $0.8 \mathrm{~cm}$.

$B$ Linear deposition of darkly stained calcium on alveolar septa. (Alizarin red.)
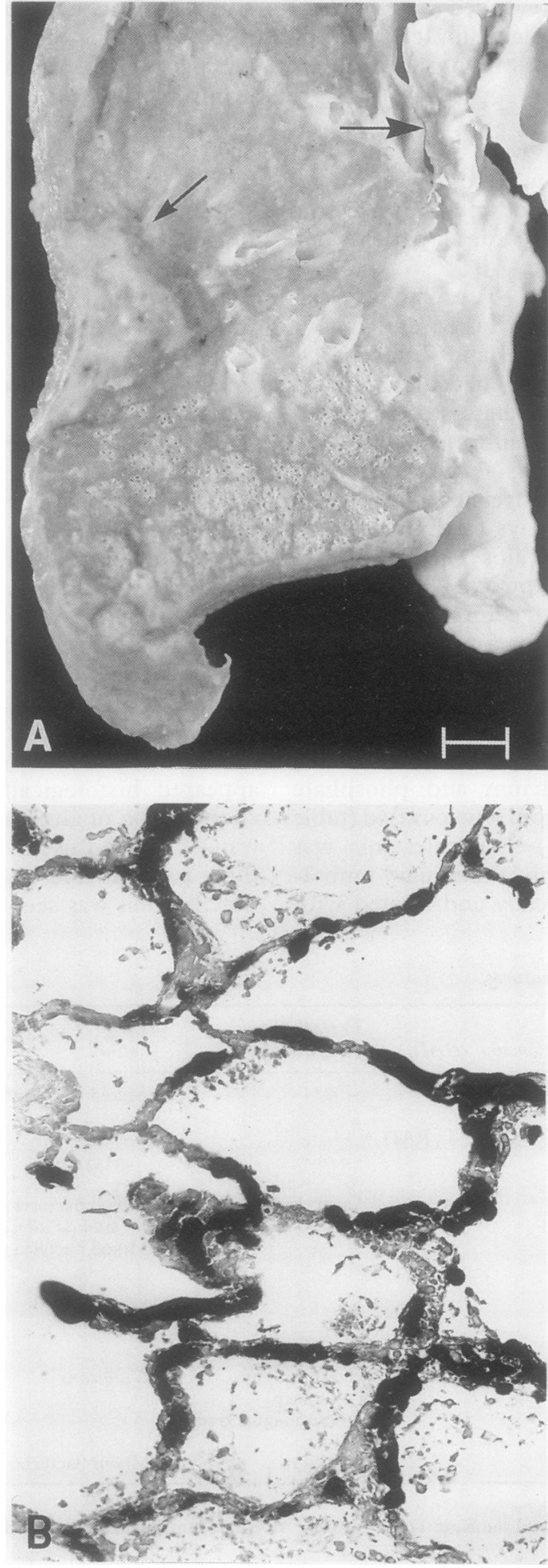

exclusively in regions of lung in which branches of the pulmonary artery were obstructed by thrombus or tumour. In patients 1 and 2 metastatic calcification was seen only in one lung distal to thromboembolic occlusion of the main and lobar pulmonary arteries (fig 1 ). In patient 4 a macroscopically segmental distribution of calcification in the right lower lobe was associated with vascular invasion by microscopic tumour (fig 2). Review of photographs of the gross appearance in this case suggested occlusion of the proximal segmental artery by tumour (fig 2). In patient 3, who had essentia thrombocythaemia, multifocal lobular zones of calcification were associated with thromboemboli in subsegmental branches of the pulmonary artery.

Review of the histological appearances in patient 5 showed minimally obstructive organising arterial thrombi or vascular invasion by tumour in parabronchial vessels of lung lobes that also showed lobular parenchymal foci of metastatic calcification. In this case we could not confirm that the obstructed vessels supplied the lung segments that contained the calcified zones. Thromboemboli in all patients were undergoing organisation and were at least one to two weeks' old. Although lung infarcts were seen in patients 1,2 , and 4 , metastatic calcification was present in non-infarcted parenchyma in all three patients (fig 1). Dystrophic calcification was also present in organising thrombi or necrotic tumour in four patients (patients 1,2 , $4,5)$. No pulmonary artery obstruction was found in patients 6 and 7, both of whom had diffuse and bilateral pulmonary metastatic calcification.

\section{Discussion}

Soft tissue calcification is divided into metastatic calcification, in which calcium salts are deposited in previously normal tissue, and dystrophic calcification, in which calcification occurs at pathologically altered sites. ${ }^{4}$ Metastatic pulmonary calcification, as this study shows, is distributed diffusely or localised..$^{5710-14}$ The factors that govern the tissue deposition of calcium include systemic derangement of calcium homeostasis and local environmental conditions within the target organs. In this study focal pulmonary metastatic calcification tended to be associated with obstruction of pulmonary arteries. We suggest that changes in the alveolar microenvironment secondary to an altered pulmonary circulation contribute to precipitation of calcium within the lung.

The main conditions that predispose to metastatic calcification include destructive (non-metabolic) bone disease, uraemia, primary hyperparathyroidism, and vitamin $\mathrm{D}$ intoxication. ${ }^{12}$ Metastatic calcification occurs most commonly in patients with renal failure, of whom $50-80 \%$ have soft tissue calcification at necropsy: ${ }^{10}$ Five of our patients had disseminated malignancy with bone metastases and six had renal failure.

In renal failure calcium and phosphate are leached from bone as a consequence of the acidosis. Failure of the kidney to hydroxylate 25-hydroxycholecalciferol and decreased ab- 

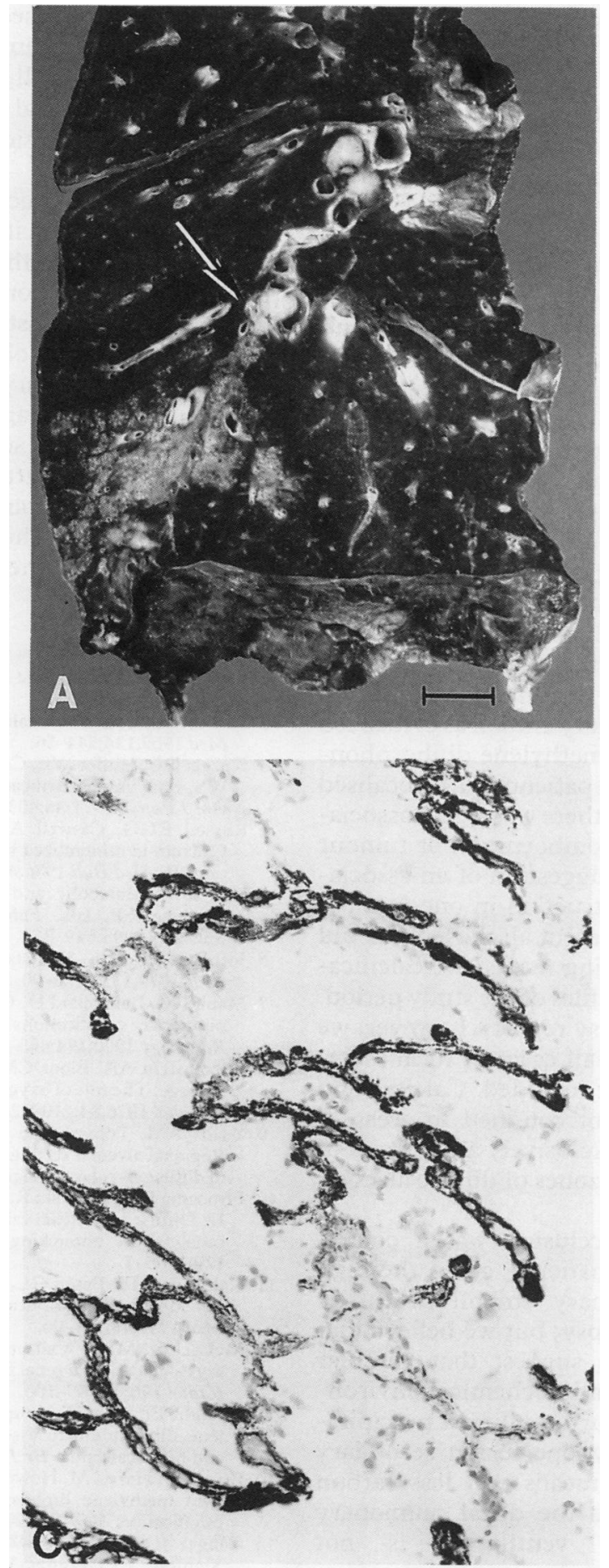

sorption of calcium from the gastrointestinal tract lead to a negative calcium balance, which stimulates secretion of parathormone and release of calcium phosphate from bone. Under these conditions, when the glomerular filtration rate is low the serum phosphate concentration rises. ${ }^{10}$ Metastatic soft tissue calcification may occur in both dialysed and non-dialysed patients, but may be accentuated after haemodialysis. ${ }^{231516}$

Malignant bone lesions can also give rise to metastatic calcification. In nine of 14 patients studied by Kaltreider et al metastatic calcification was associated with malignancy. ${ }^{11}$ Seven of these had evidence of bone destruction and five had hypercalcaemia. Patients with a low serum calcium concentration had a raised serum phosphate concentration, emphasising the fact

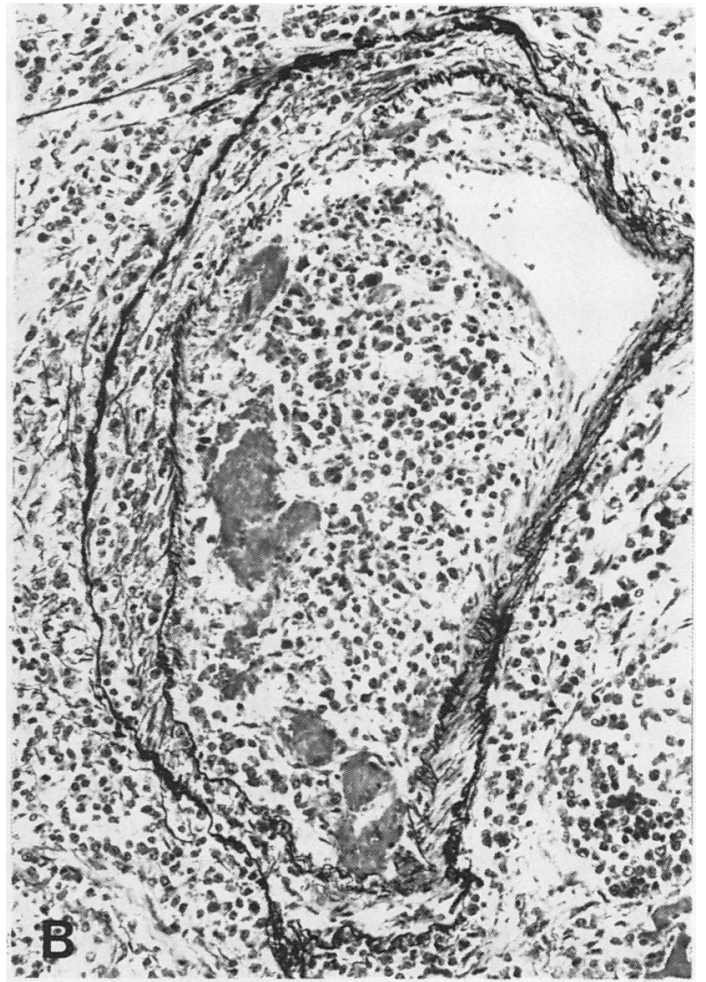

Figure 2 Patient 4: A Coronally sliced right lung. Metastatic calcification is present in a segmental distribution extending from a tumour nodule affecting the bronchovascular unit (arrow). The scale bar is $1.4 \mathrm{~cm}$. $B$ Muscular pulmonary artery infiltrated and obstructed by undifferentiated small cell carcinoma. (Movat pentachrome.) C Alveolar walls diffusely encrusted by calcium in a reticular pattern. (Haematoxylin and eosin.)

that metastatic calcification may be seen with either a normal or a depressed serum calcium concentration.

Serum calcium and phosphate were increased in five of our patients. The two patients with generalised pulmonary calcification had higher serum calcium concentrations and more widespread extrapulmonary calcification than did the patients with focally distributed calcification. Raised serum calcium and phosphate concentrations, leading to a calcium-phosphate ion product greater than 70 , are thought to be important in soft tissue calcium precipitation, ${ }^{2}$ though several studies have shown no correlation between metastatic calcification and the calcium-phosphate ion product. ${ }^{315}$ Only three of our patients had a calcium-phosphate ion product greater than 70.

In the setting of an abnormal calcium balance the visceral chemical microenvironment influences the tissue precipitation of calcium. The stomach, kidneys, lungs, and heart are the organs affected most commonly. Organs concerned with hydrogen ion production or excretion are thought to be particularly susceptible to calcification owing to the relative tissue alkalosis that accompanies cellular metabolism at these sites. ${ }^{212}$ Postdialysis alkalosis is thought to enhance the formation of metastatic calcification in uraemic patients in a similar way. ${ }^{31516}$ Shear and Kramer showed that the critical calcium-phosphate ion product for precipitation is raised as the $\mathrm{pH}$ is lowered. ${ }^{17}$ 
The primary target of metastatic calcification is the lung; ${ }^{111}$ this occurred in $75 \%$ of Mulligan's cases and in all the patients studied by Kaltreider and colleagues. ${ }^{11}$ Pulmonary metastatic calcification may be diffuse or focally distributed. In our series localised calcification was more common. Within the lung the upper lobe is more commonly affected. ${ }^{561518}$ The higher ventilation:perfusion ratio in the lung apex relative to the base, resulting in a lower alveolar carbon dioxide tension $\left(\mathrm{PCO}_{2}\right)$ and higher tissue $\mathrm{pH}$, may be responsible ${ }^{6718}$ as relative alkalinity favours precipitation of calcium phosphate. ${ }^{17}$ The blood $\mathrm{pH}$ at the apex is about 7.51 , compared with 7.39 at the base. ${ }^{619}$

A similar mechanism may favour the pulmonary calcification that may follow thromboembolic obstruction of pulmonary arteries. In previous morphological studies of localised or diffuse metastatic pulmonary calcification vascular obstruction has not been emphasised. $^{3511121620}$ Only in the case of Wraight was there a suggestion of lung calcification associated with pulmonary emboli as evidenced by a technetium- $99 \mathrm{~m}$ methylene diphosphonate scan. ${ }^{13}$ In our five patients with localised metastatic calcification there was a clear association with proximal thromboemboli or tumour emboli in four and a suggestion of an association with vascular obstruction in one (patient 5). These patients represent all those we could readily identify as having metastatic calcification from our necropsy files of the study period. As we relied on necropsy reports, however, we cannot be certain that all cases of focal metastatic calcification were included. Calcification in our patients was not confined to areas of infarction, nor did it exclusively affect areas of bronchopneumonia or zones of diffuse alveolar damage.

Perhaps vascular occlusion was a coincidental finding in our patients, given the high prevalence of pulmonary emboli in earlier reports found at necropsy; but we believe that this is unlikely. ${ }^{21}$ We suggest that vascular obstruction alters the microchemical environment of the lung, favouring calcium precipitation. Theoretically, hypoperfusion secondary to pulmonary emboli means that less carbon dioxide is delivered to the distal pulmonary capillary bed. ${ }^{22}$ As ventilation is not

Figure 3 Proposed mechanism relating pulmonary arterial obstruction to metastatic pulmonary calcification (see text).

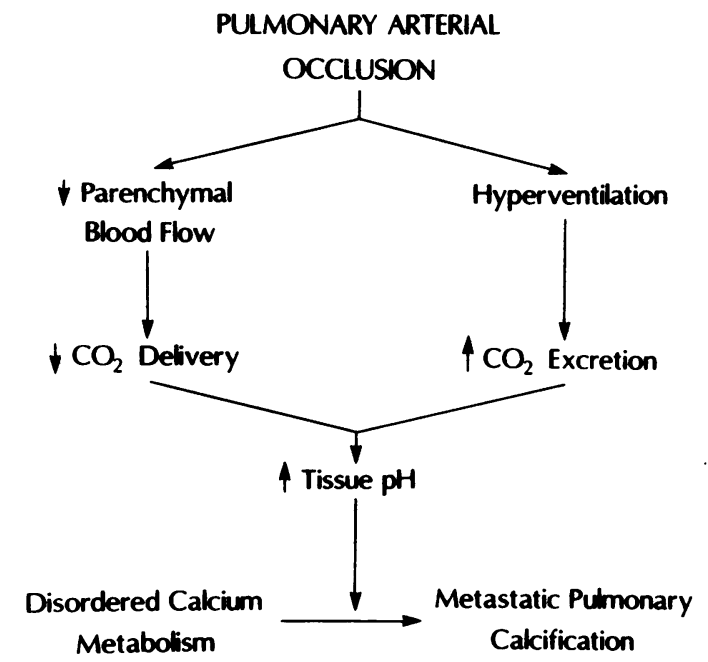

immediately decreased and may even be increased after pulmonary embolism the alveolar $\mathrm{PCO}_{2}$ will fall, leading to local tissue alkalosis, the optimal condition for calcium phosphate precipitation ${ }^{212}$ as outlined in figure 3.

Many factors interact to influence the evolution of metastatic calcification of the lung. Our study suggests that the finding of metastatic pulmonary calcification at necropsy or by open lung biopsy should instigate a careful search for pulmonary vascular obstruction. The clinical diagnosis of pulmonary metastatic calcification is difficult, but the diagnosis may be suggested by technetium lung scanning or dual energy digital chest radiography. ${ }^{1122324}$ The possibility of concomitant pulmonary vascular obstructive lesions should be borne in mind, particularly when the calcification is focally distributed.

1 Mulligan RM. Metastatic calcification. Arch Pathol 1947; 43:177-230.

2 Parfitt AM. Soft-tissue calcification in uremia. Arch Intern Med 1969;124:544-56.

3 Kuzela DC, Huffer WE, Conger JD, Winter SD, Hammon WS. Soft tissue calcification in chronic dialysis patients. Am J Pathol 1977;86:403-24.

4 Russell RGG, Caswell AM, Hearn PR, Sharrard RM. Calcium in mineralized tissues and pathological calcification. Br Med Bull 1986;42:435-46.

5 Dail DH. Metabolic and other diseases. In: Dail DH Hammar SP, eds. Pulmonary Pathology. New York: Springer 1988:549-81

6 Jost RG, Sagel SS. Metastatic calcification in the lung apex. AJR 1979;133:1188-90.

7 Mani TM, Lallemand D, Corone S, Mauriat P. Metastatic pulmonary calcifications after cardiac surgery in children. Radiology 1990;174:463-7.

8 Katzenstein AA, Bloor CM, Liebow AA. Diffuse alveolar damage. The role of oxygen, shock and related factors. $A m$ J Pathol 1976;84:210-22.

9 Yazdy AM, Tomashefski JF Jr, Yagan R, Kleinerman J. Regional alveolar damage (RAD), a localized counterpart of diffuse alveolar damage. Am J Clin Pathol 1989;92:10-5.

10 Firooznia H, Pudlowski R, Golimbu C, Rafii M, McCauley $D$. Diffuse interstitial calcification of the lungs in chronic renal failure mimicking pulmonary edema. $A J R$ 1977; 129:1103-5.

11 Kaltreider HB, Baum GL, Bogaty G, McCoy MD, Tucker M. So-called "metastatic" calcification of the lung. $A m J$ Med 1969;46:188-96.

12 McLachlan MSF, Wallace M, Seneviratne DCP. Pulmonry calcification in renal failure. Report of three cases. $\mathrm{Br}$ Radiol 1968;41:99-106.

13 Wraight EP. Focal lung uptake of technetium 99m methylene diphosphonate associated with pulmonary emboli and hypercalcemia. Br J Radiol 1983;56:345-9.

14 Brigg DJ, Harris M, Howell A. Lung uptake of technetium $99 \mathrm{~m}$ methylene diphosphonate due to focal metastaic calcification. Br J Radiol 1984;57:758-61.

15 Conger JD, Hammond WS, Alfrey AC, Contiguglia SR, Stanford RE, Huffer WE. Pulmonary calcification in chronic dialysis patients. Ann Intern Med 1975;83:330-6.

16 Editorial: Metastatic calcification and dialysis. BMJ 1972 1:762-3.

7 Shear MJ, Kramer B. composition of bone; physicochemica mechanisms. J Biol Chem 1928;79:125-45.

18 Kuhlman JE, Ren H, Hutchins GM, Fishman EK. Fulmin ant pulmonary calcification complicating renal transplantation: CT demonstration. Radiology 1989;173:459-60.

19 West JB. Regional differences in blood flow and ventilation in the lung. In: Caro CG, ed. Advances in respiratory physiology. Baltimore: Williams and Wilkins Company, 1966;198-254.

20 Heath D, Robertson AJ. Pulmonary calcinosis. Thorax 1977;32:606-11.

11 Rosenow EC III, Osmundson PJ, Brown ML. Pulmonary embolism. Mayo Clin Proc 1981;56:161-78.

22 Crofton J, Douglas A. Respiratory diseases. Oxford: Blackwell, 1969:453-68.

23 Rosenthal DI, Chandler HL, Azizi F, Schneider PB. Uptake of bone imaging agents by diffuse pulmonary metastatic calcification. AJR 1977;129:871-4.

24 Sanders C, Frank MS, Rostand SG, Rutsky EA, Barnes GT, Fraser RG. Metastatic calcification of the heart and lungs in end-stage renal disease: detection and quantification by in end-stage renal disease: detection and quantification by 881-7. 